\title{
Diagnóstico laboratorial das meningites bacterianas
}

\author{
Laboratory diagnosis of bacterial meningitis
}

\begin{abstract}
Fernanda Machado Fonseca ${ }^{1}$, Synara Cecília de Santana ${ }^{2}$, Marcela Machado Fonseca ${ }^{3}$, Ana Paula Sarreta Terra ${ }^{4}$, Ronaldo Rodrigues Sarmento ${ }^{5}$

${ }^{1}$ Mestre em Patologia Clínica. Laboratório de Microbiologia - Departamento de Ciências Biológicas - Universidade Federal do Triângulo Mineiro; ${ }^{2}$ Biomédica. Universidade de Uberaba; ${ }^{3}$ Acadêmica de Medicina - Faculdades Integradas Pitágoras; ${ }^{4}$ Biomédica da Universidade Federal do Triângulo Mineiro; ${ }^{5}$ Biomédico. Professor do curso de Biomedicina da Universidade de Uberaba.
\end{abstract}

\begin{abstract}
Resumo
A despeito dos avanços tecnológicos em relação ao diagnóstico, à patogênese e ao tratamento, a meningite bacteriana ainda permanece como importante doença de distribuição mundial, cujo diagnóstico se apoia, principalmente, no exame bacteriológico. Mesmo com o avanço das técnicas moleculares, o diagnóstico microbiológico continua sendo amplamente utilizado e, portanto, merece atenção especial. O objetivo deste trabalho foi realizar um levantamento bibliográfico sobre os principais métodos microbiológicos para o diagnóstico das meningites bacterianas e seus principais agentes causadores, visto que a identificação precisa do agente etiológico permite a correta utilização da terapia farmacológica, o que diminui significativamente os riscos de desenvolvimento de sequelas neurológicas.

Palavras-chave: Meningite bacteriana. Meios de cultura.
\end{abstract}

\section{Abstract}

Despite technological advances in the diagnosis, pathogenesis and treatment, bacterial meningitis still remains an important disease of worldwide distribution in which the diagnosis relies mainly on bacteriological examination. Even with the advances in molecular techniques, microbiologic diagnosis is still widely used and therefore deserves special attention. The aim of this study was a literature review on the main microbiological methods for diagnosis of bacterial meningitis and its main agents, since the precise identification of the agent allows the correct use of drug therapy which significantly reduces the risk of developing neurological sequelae.

Keywords: Meningitis bacterial. Culture Media.

\section{INTRODUÇÃO}

A meningite bacteriana é uma infecção severa do sistema nervoso central (SNC) e constitui uma das principais emergências médicas. A meningite consiste basicamente na inflamação das meninges e pode ser causada por agentes virais, fungos ou bactérias ${ }^{1}$. A infecção ocorre dentro do espaço subaracnoideo, e os sintomas mais comuns incluem a cefaleia, vômitos, febre, rigidez de nuca, sonolência e enjoos ${ }^{2}$. Devido à gravidade dos casos, o diagnóstico precoce é fundamental para o tratamento, a fim de se evitarem sequelas neurológicas e, nos casos mais graves, a evolução ao óbito do paciente. ${ }^{3}$

A meningite bacteriana continua sendo um problema de saúde pública, sobretudo nos países em desenvolvimento. Atualmente, cerca de $5 \%$ a $40 \%$ das crianças ainda morrem em decorrência de meningite bacteriana, na dependência, entre outros fatores, da idade do paciente e do patógeno envolvido. As sequelas

Recebido em 08 de novembro de 2010; revisado em 16 de abril de 2011. Correspondência / Correspondence: Fernanda Machado Fonseca Rua do Carmo 377 Bairro Abadia, Uberaba - MG cep: $38025-000$ neurológicas ocorrem em $5 \%$ a $30 \%$ dos sobreviventes, e devem-se, principalmente, ao retardo no estabelecimento do diagnóstico e no início do tratamento antimicrobiano eficaz. ${ }^{4}$

A meningite bacteriana, também denominada piogênica, compromete o sistema nervoso e pode causar graves sequelas. Com relação à prevalência do agente etiológico, o Streptococcus do grupo B e os bacilos gramnegativos são encontrados com maior frequência em neonatos, entre o nascimento e o primeiro mês de idade. Em crianças de até os cinco anos de idade, Haemophilus influenzae é o agente etiológico predominante, enquanto que, em crianças acima de cinco anos, o microrganismo predominante é a Neisseria meningitidis. Em pacientes idosos e imunodeprimidos, o agente etiológico identificado com maior frequência é a Listeria monocytongenes ${ }^{5,6,7}$. Escherichia coli, Klebsiella ssp, Staphylococcus aureus também já foram descritos como agentes causadores de meningite bacteriana, porém em menor proporção. ${ }^{7}$

Mantense et al. ${ }^{4}$ estudaram um total de 415 crianças internadas com diagnóstico de meningite bacteriana e demonstraram que o agente etiológico foi identificado em 315 pacientes (75,9\%), sendo, de modo 
definitivo, em 289 (69,3\%) e presuntivo, por intermédio da bacterioscopia em $26(6,6 \%)$. Os agentes mais comumente identificados foram o Haemophilus influenzae $(54,2 \%)$, o meningococo $(20,6 \%)$ e o pneumococo (18,1\% dos 315 pacientes). Houve um predomínio do acometimento de crianças com idade até 48 meses pelo Haemophilus influenzae, particularmente em relação ao meningococo. A letalidade geral foi de 10,1\%, com diferença significante entre a letalidade do pneumococo, de $17,5 \%$, e a do meningococo, de 4,6\%.

Estudos realizados em diversas áreas do mundo indicam que três tipos de bactérias são responsáveis por mais de $90 \%$ das meningites bacterianas fora do período neonatal, sendo elas: Haemophilus influenzae, Neisseria meningitidis e o Streptococcus pneumoniae ${ }^{4,8}$. A meningite tuberculosa, causada pelo Mycobacterium tuberculosis, se apresenta como uma complicação precoce da tuberculose primária e ocorre com maior frequência nos primeiros seis meses após a infecção. ${ }^{9,10}$

O diagnóstico das meningites é feito a partir da análise do líquido cefalorraquidiano (LCR), através da cultura, e bacterioscopia, além de outros exames complementares ${ }^{8}$. A realização da semeadura em meios de cultura selecionados e a bacterioscopia precisa são importantes para o diagnóstico e o tratamento da meningite, pois permite a identificação do agente causador. Sendo assim, é de grande valia esclarecer o procedimento correto a ser seguido, a fim de que se possa obter um resultado seguro e preciso.

\section{Exame do Líquido Cefalorraquidiano (LCR)}

O LCR é um líquido estéril, geralmente claro, de aspecto aquoso e transparente. É produzido nos plexos coroides, e uma das suas funções mais importantes é a de proteger o sistema nervoso central, agindo como amortecedor contra choques. Apresenta concentração de glicose entre 45 e $100 \mathrm{mg} / \mathrm{dL}$, dependendo do nível de açúcar no sangue e da concentração de proteínas entre 14 e $45 \mathrm{mg} / \mathrm{dL}$, sendo, portanto, de composição química pobre em proteínas ${ }^{3}$. É coletado para diagnosticar meningite, mielite e, menos frequentemente, encefalite viral. Preferencialmente, a punção liquórica pode ser realizada na região lombar, entre $\mathrm{L} 1$ e S1, sendo mais indicados os espaços L3-L4, L4-L5 ou L5-S1, embora possa ser obtido por meio de punção via suboccipital e cisternal. ${ }^{11,12}$

Por se tratar de um procedimento diagnóstico invasivo, o exame do LCR só deve ser realizado após a assinatura do TCLE (Termo de Consentimento Livre e Esclarecido) pelo doente ou por seu representante legal, de acordo com a Resolução 196 do Conselho Nacional de Saúde (CNS) de 10 de outubro de $1996 .{ }^{13}$

A assepsia da pele deve ser feita de forma adequada e cuidadosa, para evitar a contaminação do material estéril, o qual, tipicamente, é enviado ao laboratório em três tubos de vidro. O primeiro tubo é utilizado para a contagem de células e para as colorações diferenciais; o segundo para a cultura e preparação de esfregaços, que devem corados com o gram ou outras colorações específicas; no terceiro tubo, são realizados testes bioquímicos, como dosagem de proteína e glicose, e, quando indicado, testes especiais, tais como o antígeno criptocócico, teste sorológico para sífilis, outros estudos sorológicos e citologia. ${ }^{5}$

A amostra deve ser transportada imediatamente ao laboratório e nunca deve ser refrigerada durante o transporte ${ }^{3}$. Um dos aspectos avaliados no exame macroscópico do LCR são as alterações na coloração, observadas em alguns casos. A pleocitose confere uma aparência turva ou de vidro fosco e é detectada quando há presença de 200 hemácias $/ \mathrm{mm}^{3}$ ou mais. A presença de hemácias $\left(1.000\right.$ a $\left.6.000 / \mathrm{mm}^{3}\right)$ confere uma coloração rosa-turva a vermelha, o que confere aspecto eritrocrômico ao LCR. A presença de bilirrubina (indicativo de fase tardia pós-hemólise) confere uma coloração amarelada ou xantocrômica. ${ }^{12}$

Nos casos em que o LCR se encontra com aspecto hemorrágico, é necessário distinguir se esse aspecto é decorrente de uma hemorragia ou de um acidente de punção (traumático). Na punção traumática, o número de hemácias no segundo e no terceiro tubo, obtido durante a coleta, geralmente é progressivamente menor, a pressão liquórica costuma ser normal, e, se um grande volume de sangue for misturado ao líquor, ele coagulará ou formará teias fibrosas. Esse fato não é observado nos casos de hemorragia preexistente, visto que o sangue se encontra diluído ao LCR e desfibrinado. Após centrifugação, o líquor sanguinolento apresentará um sobrenadante incolor nos casos de punção traumática, apenas com grandes volumes de sangue ( $>100.000$ hemácias $\left(\mathrm{mm}^{3}\right){ }^{3,12}$

A coloração xantocrômica é observada nos casos de icterícia grave, em que a bilirrubina direta e indireta se difunde para o LCR. A elevação no nível de proteínas por qualquer causa confere ao líquor opacidade e coloração amarelada, a qual só é observada a olho nu, nesse caso, quando a concentração das proteínas é superior a $150 \mathrm{mg} / 100 \mathrm{~mL} .^{8}$

Em relação aos níveis encontrados de proteínas no sangue ( 5.500 a $8.000 \mathrm{mg} / \mathrm{dL})$, o teor de proteínas no líquor é pequeno $(45 \mathrm{mg} / \mathrm{dL})$, e normalmente equivale a $1 \%$ do nível sanguíneo, sendo que $80 \%$ dessas proteínas são provenientes do plasma. As proteínas no LCR podem estar elevadas em diferentes patologias, como meningite (especialmente bacteriana), doenças neurológicas, tumores entre outras. Essa elevação pode ser decorrente da alteração da permeabilidade da barreira hematoencefálica. A fração albumina no líquor está aumentada em várias doenças do SNC que aumentam a permeabilidade da barreira hematoliquórica. Certas enzimas com origem no cérebro, em especial a creatinocinase (CK-BB), também são encontradas no líquor após acidente vascular cerebral (AVC) ou traumatismo. ${ }^{8}$ 
Os níveis de glicose no LCR correspondem a $2 / 3$ da glicose sanguínea de jejum. São considerados anormais os valores de glicose inferiores a $40 \mathrm{mg} / \mathrm{dL}$ e (ou) relações inferiores a 0,3. As doenças neurológicas não alteram as concentrações liquóricas de cloro, sódio e magnésio. ${ }^{3}$

Normalmente, o LCR não contém célula alguma, ou, no máximo, até cinco linfócitos ou outras células mononucleares por $\mathrm{mm}^{3}$. O aumento de leucócitos pode significar processo reativo a bactérias ou outros agentes infecciosos, sangue, substâncias químicas, vasculite, neoplasia. ${ }^{12}$

\section{Análise microbiológica}

De acordo com o material a ser analisado, os meios de cultura devem ser selecionados cuidadosamente, com a finalidade de fornecer condições ideais de crescimento para os patógenos comumente encontrados no tipo de espécime em questão. 0 crescimento dos microrganismos nos diferentes meios de cultura utilizados fornece as primeiras informações para a sua identificação. É importante conhecer o potencial de crescimento de cada meio de cultura e adequar ao perfil bacteriano esperado para cada material. ${ }^{3}$

Os meios utilizados para semeadura do líquor são Ágar Chocolate, Ágar Sangue, Tioglicolato e ainda outros menos utilizados, como o Eosina azul de metileno (EMB), Ágar Sabouraud e Mycosel (fungos). O meio específico para pesquisa de Neisseria meningitidis é o Thayer Martin. ${ }^{5}$

Poucos são os microorganismos que comumente causam meningite bacteriana, e é por essa razão que poucos meios são rotineiramente requeridos para a inoculação primária de $\mathrm{LCR}^{8}$. Um bom meio de cultura que demonstra ação hemolítica das colônias é o Agar suplementado com sangue. ${ }^{5}$

O Ágar Sangue é um meio altamente nutritivo, utilizado para o crescimento da maioria dos germes causadores de infecção. No entanto, é particularmente útil no isolamento e identificação de patógenos exigentes e para a determinação da atividade hemolítica de algumas bactérias. Além da base para preparo do Ágar Sangue, vários outros meios são utilizados na preparação desse meio com excelentes resultados, como é o caso do Ágar Mueller Hinton. A base nutritiva oferece ótimas condições de crescimento aos microorganismos presentes. $\mathrm{O}$ pH do meio $(6,8)$ é especialmente favorável para a conservação dos eritrócitos e para a formação de halos claros de hemólise. A verificação da capacidade hemolítica é particularmente importante na escolha dos testes complementares e diferenciais do gênero Streptococcus. ${ }^{14}$

O Ágar Chocolate é preparado a partir de uma base rica (Ágar Muller-Hinton, Ágar Columbia, Ágar GC) e adicionando-se um percentual de 5 a $10 \%$ de sangue desfibrinado de carneiro em condições assépticas.
Contém hemina (fator $X$ ) e nicotina adenina dinucleotídeo (NAD/fator V), que são substâncias indispensáveis para o crescimento de bactérias do gênero Haemophilus spp. e outras bactérias fastidiosas, como a Neisseria spp. e Streptococcus pnemoniae, que não se desenvolvem bem no Ágar Sangue. Além disso, utiliza-se uma placa de Ágar EMB ou de Ágar MacConkey, incubadas nas mesmas condições de temperatura e tempo. ${ }^{5,15}$

Os bacilos gram-negativos são separados dos gram-positivos a partir do isolamento obtido em Ágar MacConkey, que adicionalmente divide as colônias em lactose-positiva e lactose-negativa, o que o torna um meio seletivo e diferencial. ${ }^{3}$

O Tioglicolato é um meio utilizado para cultivo e isolamento de germes microaerófilos, anaeróbios estritos e facultativos. As substâncias redutoras (tioglicolato e cisteína) proporcionam uma anaerobiose suficiente, inclusive para anaeróbios exigentes. A elevada viscosidade do meio impede a penetração rápida de oxigênio. Uma eventual elevação da concentração de oxigênio se manifesta por uma viragem a rosa do indicador redox resazurina. ${ }^{2,3}$

O meio de cultura Thayer Martin contém, na sua base, além de nutrientes, amido de milho, que tem a função de absorver os produto tóxicos do metabolismo das neisserias e tampões fosfatos para amenizar as trocas de $\mathrm{pH}$, devido à produção de aminas, as quais afetam a viabilidade dos agentes. É um meio enriquecido com fatores de crescimento, o que proporciona um desenvolvimento mais rápido dessas bactérias. Por fim, é um meio acrescido de suplemento de antibióticos, o que favorece o crescimento de Neisseria gonorrhoeae $e$ Neisseria meningitidis, inibindo o crescimento de microrganismos indesejáveis presentes em sítios com flora mista. ${ }^{2}$

O Ágar Mycosel é um meio útil para isolar fungos patogênicos a partir de amostras altamente contaminadas com diferentes tipos de flora acompanhante. Nessa formulação, além da adição de antibiótico, acrescenta-se a cicloheximida (actidione), com a função de inibir o crescimento de fungos contaminantes do ar, os quais dificultam o crescimento e a visualização dos fungos patogênicos. No entanto, a cicloheximida não tem ação seletiva apenas para fungos contaminantes, podendo inibir o crescimento de vários fungos patogênicos, tais como Criptococcus neoformans e várias espécies de Cândida. ${ }^{16}$

O processamento do líquor para a cultura bacteriana de rotina inclui preparação de um esfregaço para coloração com gram e cultura ${ }^{14}$. Para detecção de meningite bacteriana, a coloração de gram possui uma sensibilidade de $60 \%$ a $90 \%$, quando realizada por pessoal gabaritado, dependendo da quantidade e do tipo de organismos presentes. O limite de detecção é de aproximadamente $10{ }^{5}$ unidades de colônias em formação/mL. ${ }^{5}$ 
O diagnóstico precoce da meningite tuberculosa é extremamente difícil. As colorações fluorescentes auramina-rodamina são recomendadas pela maior sensibilidade e devem ser confirmadas com uma coloração ácido-resistente, a qual pode ser realizada na mesma lâmina. Grandes volumes de LCR são recomendados para assegurar a máxima sensibilidade da cultura, que varia de $75 \%$ a $90 \% .^{5,15}$

O material deve ser centrifugado e semeado nos meios Ágar Sangue e Ágar Chocolate enriquecido, tendo como base o Ágar Muller Hinton, a fim de que sejam atingidas praticamente todas as alternativas. A incubação deve ser realizada a uma temperatura de $35^{\circ}$ C durante 18 a 24 horas, com umidade e proporção de 5 a $10 \%$ de $\mathrm{CO} 2$. Após crescimento bacteriano, é realizada uma bacterioscopia pelo método de Gram, quando se verifica a morfologia bacteriana e a presença ou não de contaminação por outras bactérias. Em casos de contaminação, é feito um reisolamento, para posteriormente se proceder à identificação em cultura pura. ${ }^{3}$

Com o crescimento de diplococos gram-negativos com morfologia semelhante à de Neisseria em Ágar Chocolate, deve-se realizar a prova da oxidase, seguida de identificação bioquímica através da semeadura em tubos de Ágar Cystine Tripticase (CTA) com os carboidratos dextrose, maltose, sacarose e lactose..$^{1,15}$

O meningococo, crescendo em $37^{\circ} \mathrm{C}$, de preferência em atmosfera de $\mathrm{CO}_{2}$ e umidade, degrada apenas dextrose e maltose. Essas características, juntamente com o teste da oxidase positivo e crescimento no Ágar Chocolate, identificam a bactéria Neisseria meningitidis. Em meio sólido, as colônias de meningococos são convexas, transparentes, nãopigmentadas, não-hemolíticas e com aproximadamente 1 a $5 \mathrm{~mm}$ de diâmetro. ${ }^{1,3}$

No caso de o microrganismo encontrado apresentar a forma de bacilo gram-negativo pleomórfico e só se desenvolver no Ágar Chocolate e com muita dificuldade nos meio que contenham sangue, pode-se afirmar, presuntivamente, que se trata de um bacilo do gênero Haemophilus, provavelmente o Haemophilus influenza. O teste de utilização dos fatores X e V por amostras de Haemophilus e a prova de satelitismo são realizados para a confirmação do diagnóstico e também para uma investigação mais detalhada. A prova do satelitismo é realizada quando a semeadura de Haemophilus é feita em ágar sangue de carneiro, transpassando na superfície do meio de cultura uma linha de semeadura de Staphylococcus aureus. As colônias de Haemophilus crescem ao redor do alo de hemólise do S. aureus, originando, assim, o nome "satelitismo". ${ }^{17}$

Os estreptococos são exigentes quanto aos nutrientes do meio de cultura. Caldo ou ágar enriquecido com triptose de soja ou infusão de coração bovino, proteose peptona ou caldo Todd-Hewitt são os mais indicados. Esses meios são livres de açúcares redutores ou de substâncias que influenciam a expressão ßhemólise pelos estreptococos. ${ }^{1}$

As listérias são bacilos gram-positivos nãoesporulados, anaeróbio-facultativos. Nos esfregaços de LCR corado pelo gram, a listéria se encontra intra ou extracelularmente, podendo ser confundida com pneumococo, estreptococos e, se excessivamente descorada, com hemófilos. Listeria monocytogenes cresce bem em caldo com infusão de coração bovino (BHI) ou em placas de ágar contendo $5 \%$ de sangue de coelho ou carneiro. No ágar sangue, dentro de 18 a 24 horas, ocorre ß-hemólise visível ao redor ou abaixo das colônias. Todas as espécies de listéria são produtoras de catalase. A identificação presuntiva dentre as diversas espécies se faz pelas provas de hemólise, mobilidade, redução de nitrato e fermentação de açúcares. ${ }^{3,5}$

Para detecção de meningite por enterobactérias, as culturas obtidas em caldo de enriquecimento devem ser repicadas em ágar MacConkey, que é um meio diferencial para enterobactérias. Além dos nutrientes proteicos e da lactose, o ágar MacConkey contém sais biliares e cristal violeta, que inibem o crescimento de bactérias gram-positivas, e vermelho neutro, que é um indicador colorimétrico que serve para distinguir os gram-negativos fermentadores ou não de lactose. As bactérias fermentadoras de lactose desenvolvem colônias vermelhas, enquanto as não-fermentadoras desenvolvem colônias transparentes ${ }^{9}$. Uma vez isoladas, as colônias bacterianas devem ser submetidas às demais provas diferenciadoras para enterobactérias e outros bacilos gram-negativos. A presença dos bacilos gram-negativos nãofermentadores também pode ser observada no LCR e, nesse caso, o microrganismo mais comumente encontrado é Pseudomonas spp. ${ }^{1,18}$

A despeito dos avanços tecnológicos em relação ao diagnóstico, à patogênese e ao tratamento, a meningite bacteriana ainda permanece como importante doença de distribuição mundial, na qual o diagnóstico se apoia, principalmente, no exame bacteriológico. Tal exame permite o isolamento e a identificação do agente etiológico, que se faz essencial para o diagnóstico preciso e o tratamento adequado. Cabe ressaltar que, mesmo com o avanço das técnicas moleculares, o diagnóstico microbiológico continua sendo amplamente utilizado e, portanto, merece atenção especial.

\section{REFERÊNCIAS}

1. REQUEJO, H. I. Z. Meningites bacterianas. In: FERREIRA, A. W.; ÁVILA, S. L. M. (Org.). Diagnóstico laboratorial das principais doenças infecciosas e auto-imunes. 2.ed. Rio de Janeiro: Guanabara Koogan, 2001. cap. 18, p. 202-214.

2. VAN DE BEEK, D. et al. Clinical features and prognostic factors in adults with bacterial meningitis. N. Engl. J. Med., Boston, v. 351, n. 18 , p. 1849-1859, 2004. 
3. SANTOS FILHO, L. Cultura do Líquido Céfalo Raquidiano. In: Manual de microbiologia clínica. 3.ed. João Pessoa: Universitária/UFBP, 2003. cap. 9, p. 209-216.

4. MANTENSE, O. C. et al. Perfil etiológico das Meningites bacterianas em crianças. J. Pediatr. (Rio J.), Porto Alegre, v.78, n 6, nov./dez. 2002.

5. SMITH, G. P.; KJELDSBERG, C. R. Líquido cefalorraquidiano Sinovial e outros líquidos corporais. In: HENRY, J. B. Diagnósticos clínicos e tratamento por métodos laboratoriais. 19. ed. São Paulo: Manole, 1999. cap. 19, p. 457-467.

6. FERREIRA, A. A. A.; Alves, M. S. C. F.; Marinho, L. A. Perfil etiológico e terapêutico da meningite bacteriana aguda: contribuindo para a vigilância dos serviços de saúde. R. Ci. Méd. Biol., Salvador, v. 5, v. 2, p. 140-145, 2006.

7. SILVA, L. P. A. et al. Prevalência de sequelas auditivas pós meningite piogênica em crianças. R. Soc. Bras. Fonoaudiol., São Paulo, v. 14, p. 332-338, 2009

8. CABRAL, D. C. C. et al. A. Importance of cerebrospinal fluid control tests in bacterial meningitis cases as a discharge criterion. R. Soc. Bras. Med. Trop., Rio de Janeiro, v. 41, n. 2, p. 189 192, 2008.

9. HERINGER, R. R. et al. Localização da lesão e achados do líquido cefalorraqueano na meningite tuberculosa: diferenças nos compartimentos lombar, cisternal e ventricular. Arq. NeuroPsiquiatr., São Paulo, v. 63, n. 2b, p.543-547, jun. 2005.

10. MURTHY, J. M. Tuberculous meningitis: the challenges. Neurol India. Bombay, v. 58, n. 5, p. 716-722, 2010.
11. MACHADO, M. B. A. Meninges-Líquor. Neuroanatomia funcional. 2.ed. São Paulo: Atheneu, 2000. cap. 9, p. 75-84.

12. ADAMS, D. R.; VITOR, M.; ROPPER, H. A. Técnicas especiais para o diagnóstico neurológico. In: _____. Neurologia. 6. ed. Chile: McGraw Hill Inter-americana de Chile, 1998. cap. 2, p. 9-27

13. PUCCIONI-SOHLER, $M$. et al. Coleta do Líquido cefalorraquidiano, termo de consentimento livre e esclarecido e aspectos éticos em pesquisa. Arq. Neuro-Psiquiatr. São Paulo, v. 60 , n. $3 a$, set. 2002

14. WOODS, G. L. Coleta e manipulação de espécimes para diagnóstico de doenças infecciosas. In: HENRY, J. B. Diagnósticos clínicos e tratamento por métodos laboratoriais. 19. ed. São Paulo: Manole, 1999. cap. 54, p. 1317-1319.

15. WOODS, G. L.; AYERS, L. W.; WASHINGTON, A. J. Bacteriologia médica. In: HENRY, J. B. Diagnósticos clínicos e tratamento por métodos laboratoriais. 19. ed. São Paulo: Manole, 1999. cap. 48, p. $1135-1137$

16. BARRIOS, J. L. et al. Cryotococcal meningitis in HIV-negative patientes. Enferm Infecc Microbiol. Clin. Barcelona, n. 24, 2006. 17. CAMPOS, J. M. Haemophylus. In: Murray, P. R. et al. Manual of clinical microbiology. American Society for Clinical Microbiology. Washington D. C.; American Society for Microbiology, 1995.

18. BRASIL, Ministério da Saúde, Agência Nacional de Vigilância Sanitária. Manual de procedimento básicos em microbiologia clínica para o controle de infecção hospitalar. Brasília/DF: ANVISA, set. 2000. 